\title{
ECO INOVAÇÃO: ESTUDOS NAS BASES WEB OF SCIENCE E SCOPUS E TENDÊNCIAS PARA PESQUISAS FUTURAS ECO-INNOVATION: STUDIES IN THE WEB OF SCIENCE AND SCOPUS BASES AND TRENDS FOR FUTURE RESEARCH
}

\author{
Michele Morais Oliveira Pereira ${ }^{1}$ \\ José Willer do Prado \\ Luiz Guilherme Rodrigues Antunes ${ }^{3}$ \\ Luiz Marcelo Antonialli ${ }^{4}$ \\ Dany Flávio Tonelli ${ }^{5}$
}

\section{RESUMO}

As inovações que trazem benefícios ao meio ambiente, mesmo que este efeito não tenha sido o principal objetivo da inovação, têm sido denominadas na literatura como inovações ambientais, inovações verdes, eco inovações ou inovações sustentáveis. Este estudo objetivou identificar e descrever como está configurado o campo de pesquisa sobre eco inovação e traçar uma agenda de estudos futuros sobre o tema. Realizou-se um levantamento de artigos indexados nas bases de dados Web of Science e Scopus (Elsevier) e, posteriormente, um estudo bibliométrico e elaborou-se também uma discussão acerca das proposições para estudos futuros. Identificou-se os trabalhos mais relevantes no campo de estudo, os principais autores, periódicos e países mais proficuos, além das redes de relações entre pesquisadores. Quanto à agenda de estudos futuros, identificou-se que são recomendados estudos longitudinais, estudos comparativos, análises sobre implicações das eco inovações no desempenho organizacional, de pesquisas considerando-se as diferenças de desenvolvimento econômico dos países onde as empresas atuam e de estudos sobre pequenas e médias empresas.

Palavras-chave: Eco Inovação. Inovação Ambiental. Inovação Verde. Inovação Sustentável. Bibliometria.

Manuscript first received/Recebido em 22/10/2018 Manuscript accepted/Aprovado em: 27/06/2019

1 Mestre em Economia Doméstica. Professora na Universidade Federal de Viçosa-Campus Rio Paranaíba. Doutoranda em Administração pela Universidade Federal de Lavras. E-mail: mixmorais@ gmail.com

2 Mestre em Administração. Doutorando em Administração pela Universidade Federal de Lavras. E-mail: jwprado@ gmail.com

3 Mestre em Administração pela Universidade Federal de Lavras. E-mail: luguiantunes@yahoo.com.br

4 Doutor em Administração. Professor no Departamento de Administração e Economia, Universidade Federal de Lavras. E-mail: lmantonialli@gmail.com

5 Doutor em Administração. Professor no Departamento de Administração e Economia, Universidade Federal de Lavras. E-mail: danytonelli@gmail.com 


\section{ABSTRACT}

Innovations that bring benefits to the environment, even if this effect has not been the main goal of innovation, have been referred to in the literature as environmental innovations, green innovations, eco innovations or sustainable innovations. This study aimed to identify and describe how the field of research on eco-innovation is configured and to draw up an agenda of future studies on the theme. A research of articles indexed in the Web of Science and Scopus (Elsevier) database was carried out and, later, a bibliometric study and elaboration of propositions for future studies. They were identified the most relevant papers in the field of study, the main authors, periodicals and most profitable countries, as well as the networks of relations between researchers. As for the future study agenda, longitudinal studies, comparative studies, analyzes of the implications of eco innovations on organizational performance, of research are recommended, considering the differences in the economic development of the countries where companies operate and studies in small and medium enterprises.

Keywords: Eco Innovation. Environmental Innovation. Green Innovation. Sustainable Innovation. Bibliometry.

\section{INTRODUÇÃO}

$\mathrm{Na}$ atualidade, segundo Fraj et al. (2015), as organizações têm atuado no desenvolvimento de estratégias de proteção ambiental e também têm sido beneficiadas por ações neste sentido obtendo vantagens competitivas. Elas vêm inovando neste sentido impulsionadas pelas alterações em seu ambiente de atuação como surgimento de novos mercados, necessidade de uso eficiente dos recursos, na legislação, na preferência dos consumidores, dentre outros (PACHECO; LIBONI, 2017).

Neste sentido, tem-se a eco inovação (EI) que consiste na criação de produtos (bens e serviços), processos, métodos de marketing, estruturas organizacionais e arranjos institucionais novos ou significativamente melhorados que, intencionalmente ou não, resultam em melhorias ambientais em comparação a outras alternativas (OECD, 2009). Esta forma de inovação tem sido denominada, na literatura científica como inovação ambiental, inovação verde, eco inovação ou inovação sustentável (XAVIER et al., 2017).

AEIreduzimpactos ambientais e contribui para problemas ambientais específicos (RENNINGS, 2000). Há pressupostos de que as empresas que têm introduzido práticas com menor prejuízo à natureza em seus processos, têm-se tornado mais competitivas (REXHAUSER; RAMMER, 2014; JUNQUERA et al., 2012).

A EI é uma área jovem de pesquisa mas tem estado em foco nas preocupações recentes de acadêmicos, profissionais e decisores políticos (BOSSLE et al., 2016; DÍAZ-GARCIA, GONZÁLEZMORENO; SÁEZ-MARTINEZ, 2015). Além disso, é uma temática multi e transdisciplinar (BOONS; LÜDEKE-FREUND, 2013).

Neste sentido, evidencia-se a necessidade de identificar como está o campo de estudos sobre a temática, bem como as diretrizes colocadas pelos estudiosos da área para novos estudos. Pois, a 
partir dos estudos dos últimos anos, pode-se identificar lacunas e oportunidades para proposição de pesquisas futuras. $\mathrm{O}$ estudo é, então, relevante pois a eco inovação é uma categoria analítica ou conceitual ainda não consolidada (ANGELO; JABBOUR; GALINA, 2012).

Considerando estas informações, pergunta-se: como está a literatura científica sobre as inovações voltadas à redução de impactos ambientais? Neste sentido, o objetivo do presente estudo foi identificar e descrever como está configurado o campo de pesquisa sobre eco inovação e traçar uma agenda de estudos futuros sobre a temática. Para atingir esse objetivo realizou-se uma pesquisa bibliométrica dos artigos indexados nas bases de dados Web of Science e Scopus (Elsevier).

Este estudo é relevante pois o uso de técnicas bibliométricas auxilia no entendimento de novas temáticas, podendo auxiliar na identificação de tendências para pesquisas futuras, identificando lacunas e oportunidades no campo do saber estudado (QUEVEDO-SILVA et al., 2016). Chueke e Amatucci (2015) afirmaram que, apesar de a bibliometria ser muito utilizada no Brasil, na área de administração, especificamente, é ainda escassa a literatura especializada sobre o tema.

Sob o ponto de vista teórico, o trabalho contribui no sentido de mapear os principais trabalhos sobre o tema, os autores mais relevantes, os periódicos mais atuantes, os países de origem dos pesquisadores que mais publicam, dentre outros aspectos. Estas informações são importantes, pois podem direcionar os estudos e as propostas de pesquisadores do tema e, também, fornecer informações para parcerias com pesquisadores de outras instituições ou países.

O próximo tópico trata acerca dos estudos e abordagens mais recentes sobre a temática na literatura científica. Na sequência, são descritos os procedimentos metodológicos e, posteriormente, são apresentados os resultados e suas discussões. Em seguida, têm-se as considerações finais.

\section{ECO INOVAÇÃO}

O marco inicial da adesão das empresas às ações ambientais foi a publicação do relatório da Comissão Mundial sobre Meio Ambiente e Desenvolvimento (CMMAD), em 1987, conhecida como Comissão Brundtland (BARBIERI et al., 2010). Segundo estes autores, o movimento ocorreu nas empresas, inicialmente, de fora para dentro, devido a pressões governamentais e da sociedade civil organizada, que culpava as empresas por degradação ambiental.

Neste contexto, têm-se as inovações ambientais, que são aquelas inovações que proporcionam benefícios ao meio ambiente (KAMMERER, 2009; RENNINGS, 2000). Segundo a OECD (2009), elas abrangem novos processos, produtos ou serviços, tecnologias ou mercados. Este tipo de inovação abrange inovações em produtos, serviços ou processos de forma a minimizar o impacto causado pelas atividades empresariais (GILLI et al., 2013), ou seja, que tenham efeito benéfico ao meio ambiente, mesmo que este não seja o principal objetivo delas (BERNAUER et al., 2006).

Baseando-se nos critérios de Edmondson e McManus (2007), Pacheco e Liboni (2017) classificaram os estudos sobre as inovações que reduzem os impactos ambientais como um tema de pesquisa ainda de teoria intermediária. Elas assinalam sobre a necessidade de avanço teórico, ou seja, de estudos que estabeleçam novas relações entre esta e outras teorias já fundamentadas e que se estabeleçam também novos construtos neste sentido. 
Angelo et al. (2012) explicam que, na literatura, são utilizados três termos principais para se referir à estas inovações: inovação ambiental, inovação verde ou ainda eco inovação. Xavier et al. (2017) identificaram também a presença do termo inovação sustentável para este tipo de inovação.

Segundo a comissão da União Europeia - European Comission (2018), este tipo de inovação se relaciona às formas de inovação, tecnológicas ou não, que criam oportunidades de negócios e beneficiam o meio ambiente, evitando ou reduzindo o impacto ambiental ou otimizando a utilização dos recursos.

A EI se relaciona aos conceitos de eco eficiência e eco indústria (EUROPEAN COMISSION, 2018) e por beneficiar tanto o meio ambiente quanto a empresa, pode ser considerada, portanto, uma atuação ganha-ganha (HOJNIK et al., 2018).

Pinsky et al. (2015) analisaram quantitativamente a produção acadêmica sobre a temática na base Web of Science no período de 2008 a 2013, e, em seguida em 2014, com foco na produção brasileira. Eles concluíram que a produção acadêmica sobre esta forma de inovação, no Brasil, ainda é incipiente e recente. Identificaram nesta busca que o primeiro artigo de autores brasileiros sobre o tema foi publicado em 2008 (PINSKY et al., 2015).

Alguns fatores têm atuado como drivers à eco inovação, dentre eles: os mecanismos de regulação e as políticas (DORAN; RYAN, 2016), a pressão do mercado (DAI et al., 2015), a orientação ambiental da organização (TRIGUERO et al., 2016), o envolvimento da rede ou cadeia de suprimentos (NAIR et al., 2016) a internacionalização, a troca de conhecimentos (CHIARVESIO et al., 2015), o investimento em pesquisa e desenvolvimento (GHISETTI; PONTONI, 2015), a inovação tecnológica (SÁNCHEZ; DEZA, 2015), os sistemas de gestão ambiental e certificações (AMORES-SALVADO $e t$ al., 2015), a economia de custos (CHASSAGNON; HANED, 2015), os recursos humanos (ZAILANI et al., 2014) e a gestão por processos (LEE; KIM, 2012).

Quanto à vantagem competitiva advinda desta inovação, há evidencias de fatores como: melhor desempenho da organização (DORAN; RYA, 2016; KIM, 2015; CHIARVESIO; DE MARCHI; DI MARIA, 2015), redução de custos e aumento na rentabilidade (REXHAUSER; RAMMER, 2014; HORBACH et al., 2012), obtenção e registro de patentes (DECHEZLEPRETRE; GLACHANT, 2014) e aprendizagem organizacional e do capital humano (CHANG, 2012), dentre outros. Assim, pode-se afirmar que a eco inovação tem sido uma alternativa viável para aumentar eficiência e competitividade das organizações, impactando, positivamente, também o ambiente e a sociedade (EIO, 2013).

Quanto às barreiras à eco inovação, tem-se o estudo de Pinget et al. (2015) e o de Miklencicova e Capkovicova (2014). Ambos abordaram acerca destes obstáculos em pequenas e médias empresas europeias. Pinget et al. (2015) corroboram que a literatura é ampla quanto aos drivers da eco inovação ambiental, mas há necessidade de estudos sobre as barreiras a esta inovação.

Pinget et al. (2015) identificaram três grandes grupos de barreiras à inovação ambiental, sendo estes quanto ao custo, ao conhecimento e ao mercado. Os resultados da pesquisa de Miklencicova e Capkovicova (2014) corroboram quando afirmam que, dentre os muitos obstáculos à implementação de inovações ambientais, estão a deficiência dos preços de mercado para produtos verdes, as restrições de infraestrutura e comportamentais e a incerteza das estruturas econômicas.

Xavier et al. (2017) em seu artigo de análise sistemática acerca dos modelos de estudos de eco inovação identificou que a maioria dos modelos foram aplicados em pesquisas com empresas de 
manufatura. Os resultados do trabalho dos autores mostram uma tendência de utilização de modelos de eco inovação em processo de design, em diagramas de determinantes da eco inovação e em modelos com foco na abordagem de resolução de problemas. Eles identificaram falta de modelos relacionados aos fatores estruturais da empresa como habilidades específicas, capacidade ambiental, cultura e liderança.

\section{PROCEDIMENTOS METODOLÓGICOS}

A presente pesquisa trata-se de um estudo bibliométrico que buscou verificar as principais publicações no campo de pesquisa sobre eco inovações. Como percurso metodológico, adaptou-se o framework de pesquisa (Quadro 1) utilizado por Prado et al. (2016). Realizou-se um levantamento de artigos indexados nas bases Web of Science da Thomson Reuters e Scopus (Elsevier) no mês de julho de 2017. Considerou-se como período de análise a primeira publicação sobre o tema até as publicações do ano de 2016 porque o ano de 2017 ainda estava na metade.

Quadro 1 - Etapas para a construção da pesquisa e análise bibliométrica.

\begin{tabular}{|c|c|c|}
\hline & Etapas & Descrição \\
\hline 1 & $\begin{array}{l}\text { Seleção do objeto de } \\
\text { análise } \\
\text { e da base científica }\end{array}$ & $\begin{array}{l}\text { a) Definir o campo científico e teórico do trabalho; } \\
\text { b) Delimitar os objetivos do trabalho; } \\
\text { c) Escolher as bases científicas para as buscas dos artigos. }\end{array}$ \\
\hline 2 & $\begin{array}{l}\text { Procedimentos } \\
\text { de busca }\end{array}$ & $\begin{array}{l}\text { a) Definir os termos de busca para localizar os periódicos; } \\
\text { b) Definir os operadores para uma pesquisa avançada; } \\
\text { c) Definir os filtros de busca. }\end{array}$ \\
\hline 3 & $\begin{array}{l}\text { Coleta e organização dos } \\
\text { dados }\end{array}$ & $\begin{array}{l}\text { a) Definir o software de análise bibliométrica; } \\
\text { b) Realizar o download das referências no formado do software de análise bibliométrica e no } \\
\text { formato de planilha eletrônica; } \\
\text { c) Importar os arquivos para o software de análise bibliométrica. }\end{array}$ \\
\hline 4 & $\begin{array}{l}\text { Análise da produção } \\
\text { científica relacionada com } \\
\text { a amostra } \\
\text { (Research front) }\end{array}$ & $\begin{array}{l}\text { a) Análise do volume temporal das publicações selecionadas; } \\
\text { b) Análise de citações dos artigos selecionados; } \\
\text { c) Análise dos periódicos que mais publicaram; } \\
\text { d) Análise dos países dos artigos selecionados; } \\
\text { e) Análise das palavras-chaves dos artigos selecionados; } \\
\text { f) Análise dos cluster das categorias da Web of Science e Scopus }\end{array}$ \\
\hline 5 & $\begin{array}{l}\text { Análise da rede de } \\
\text { cocitações realizada pela } \\
\text { amostra } \\
\text { (Intellectual base) }\end{array}$ & $\begin{array}{l}\text { a) Análise da rede de cocitações dos artigos mais citados. } \\
\text { b) Análise da rede de cocitações dos periódicos mais citados. }\end{array}$ \\
\hline
\end{tabular}

Fonte: Elaborado pelos autores e adaptado de Prado et al. (2016).

Com intuito de expandir as buscas, optou-se por utilizar duas bases por saber que estas possibilitam procedimentos padronizados de busca, os quais favorecem análises futuras e também pelo fato de já se ter o conhecimento prévio de que há poucas publicações sobre os termos em língua portuguesa. Outro fator decisivo é que a Web of Science indexa mais de 12.700 periódicos e a Scopus (Elsevier) indexa mais de 18.000 periódicos.

Os termos utilizados para as buscas foram "Environmental innovation*”, "Green Innovation*”, "Eco innovation*" e "Sustainable innovation*". Os termos foram escolhidos baseando-se nos argumentos de Xavier et al. (2017), De Marchi (2012) e de Bernauer et al. (2006) onde afirmam que estes são os termos mais adequados para se identificar pesquisas que tratam acerca das inovações com resultados favoráveis ao meio ambiente. 
Para a pesquisa nas duas bases utilizou-se os seguintes critérios: 8 buscas, uma por termo em cada uma das bases. Buscou-se os termos no título e refinou-se o resultado por artigos, para melhor padronização e comparação dos resultados.

Como a busca foi realizada individualmente por cada um dos termos, reconhecia-se a possibilidade de existirem artigos duplicados nas buscas dentro de cada base porque poderiam existir artigos que possuem mais de um termo no título do trabalho. Assim, eliminou-se 1 artigo da busca no Web of Science e 2 da Scopus (Elsevier) por terem aparecido repetidos já nas buscas. Posteriormente, com o auxílio do software Excel, excluiu-se uma das cópias dos artigos identificados como duplicados nas duas bases. A Tabela 1 demonstra os resultados encontrados nas buscas e também o número de artigos duplicados que foram excluídos do corpo de análise.

Tabela 1 - Resultados das buscas (Web of Science e Scopus)

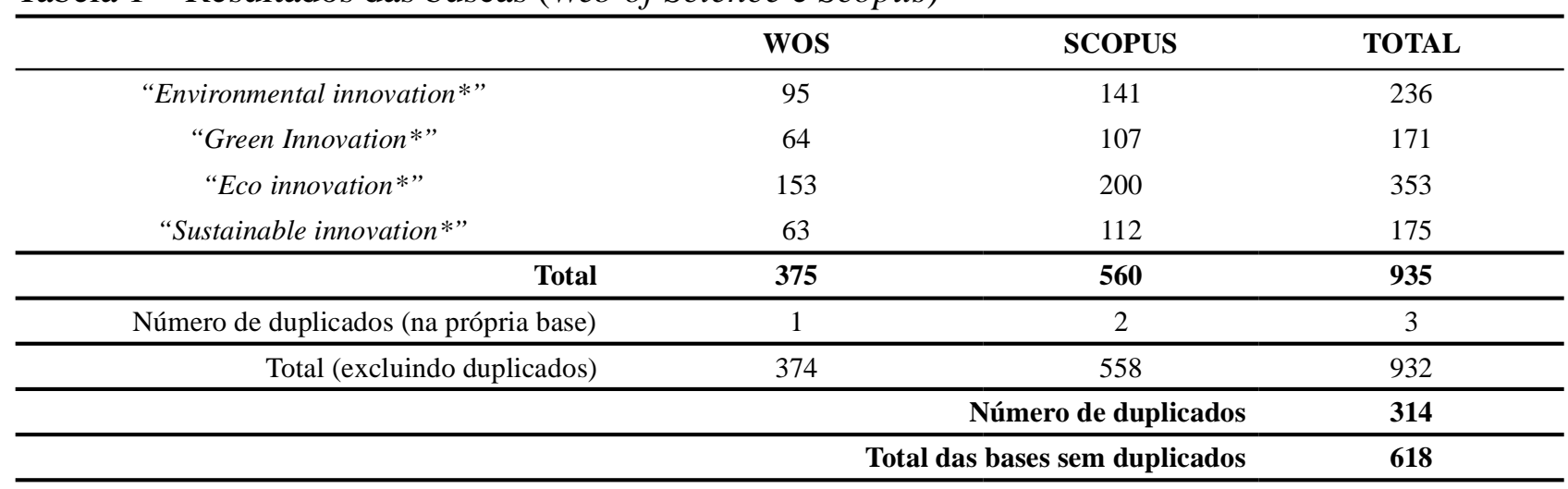

Fonte: Elaborado pelos autores.

Em pesquisas dessa natureza, segundo Chen (2006), é possível dividir os resultados em análise da produção científica relacionada à amostra (Research front) e análise da rede de cocitações realizada pela amostra (Intellectual base). A análise da Intellectual base de uma Research front rastreia as citações e cocitações na literatura científica (CHEN, 2006). A principal contribuição dessa etapa é a análise da rede de cocitações das referências utilizadas pela amostra encontrada (Research front), ou seja, os trabalhos apontados pela Intellectual base, frequentemente, não são os mesmos localizados pela busca inicial (Research front). A relevância desta análise é expandir para além das bases selecionadas inicialmente e encontrar trabalhos relevantes para o campo em estudo, que podem não estar indexados nas bases escolhidas (amostra).

A operacionalização dessa etapa foi realizada por meio da inserção dos dados levantados nas bases Web of Science e Scopus no software CiteSpace. Entretanto, para utilização dos dados da Scopus foi necessário converter os arquivos para que eles pudessem ser utilizados no CiteSpace (o próprio software realiza a conversão). Neste sentido, na conversão dos dados da Scopus para o formato WoS, foram convertidos 524 dos 558 do arquivo original scopus.ris, sendo originalmente um total de referências de 28602 validando o montante de 26017 (90.0\%), o que segundo Chen (2006), é um excelente percentual.

Elaborou-se também uma agenda para estudos futuros com base na leitura das considerações finais dos artigos da amostra publicados no ano de 2016. Foi escolhido este período por ser o ano mais recente da análise deste estudo e, acredita-se que, devido a isto, as propostas ainda não tenham 
sido executadas. Assim, os artigos foram analisados com respeito às lacunas na literatura científica identificadas pelos próprios autores dos trabalhos. Dentre os 99 artigos publicados neste período e presente nas buscas realizadas, 18 não eram acessíveis e apenas 34 incluíam sugestões de estudos futuros. Assim, agrupou-se as temáticas encontradas em 2 grupos, um sobre aspectos metodológicos e outro sobre abordagens teóricas e conceituais.

\section{RESULTADOS E DISCUSSÃO}

Neste tópico, são apresentadas as características das publicações relacionadas ao tema encontradas nas buscas realizadas para construção deste artigo e a agenda de estudos futuros.

\subsection{ANÁLISE DA PRODUÇÃO CIENTÍFICA NA AMOSTRA (RESEARCH FRONT)}

A Figura 1 apresenta a distribuição das 618 publicações sobre o assunto ao longo dos anos, bem como o número de publicações por termo pesquisado ao longo do período de tempo analisado. Verificou-se que o termo "Environmental innovation" foi o primeiro a ser utilizado nas publicações e continuou como o único termo nos títulos dos artigos publicados de 1978 até 1999. Os termos "eco innovation" $e$ "sustainable innovation" começam a ser utilizados nos títulos dos artigos nos anos 2000 e 2001. "Eco innovation” reaparece nos títulos a partir do ano de 2006 e, nos últimos anos, tem sido o mais utilizado nas publicações. O termo "green innovation" aparece nos títulos dos artigos a partir do ano de 2006. A partir deste ano, os quatro termos vêm sendo utilizados nos títulos dos artigos publicados presentes nas duas bases analisadas.

Figura 1: Número de artigos por ano (total e por termo de busca). Fonte: elaborado pelos autores.

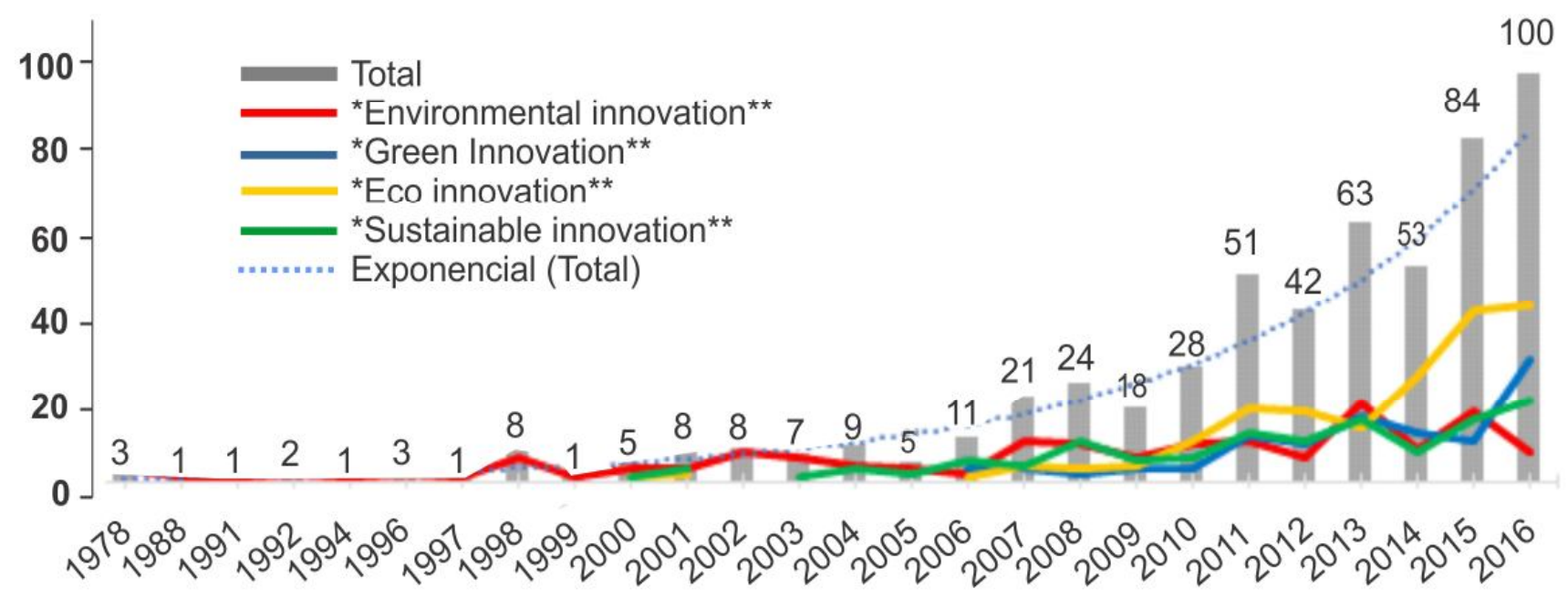

Fonte: Elaborado pelos autores.

Os dois primeiros artigos publicados foram no ano de 1978. Um é o de Taylor e Miller, denominado Adoption process and environmental innovations - case-study of a government project na revista Rural Sociology. Outro é de Kostamo, também em 1978, denominado Environmental innovations from Finland, no periódico Microtecnic. 
Do ano de 2006 para 2007 houve relevante crescimento no número de artigos sobre a temática. Esta se tornou mais frequente nos estudos nesse período devido à relevância cada vez maior desta no meio empresarial, nas políticas públicas e, possivelmente, devido ao fato do Protocolo de Kyoto ter, nominalmente, entrado em vigor em 2005. O acordo se relaciona à necessidade dos países reduzirem as emissões de carbono e, dez anos depois, evidenciou-se quase nenhum avanço nesse sentido, havendo metas de redução quase que exclusivamente por parte dos países da Europa (TUFFANNI, 2015).

Houve considerável aumento no número de publicações sobre o tema também a partir de 2011. Estes resultados refletem como o tema tem sido cada vez mais estudado no meio acadêmico e uma posspivel relação quanto a acontecimentos mundiais. Em 2012 ocorreu a aprovação do documento final da Conferência das Nações Unidas sobre Desenvolvimento Sustentável, a Rio+20. O documento traz compromissos como o fortalecimento do Programa das Nações Unidas para o Meio Ambiente (Pnuma), a criação de um Fórum Político de Alto Nível Internacional e o desenvolvimento sustentável com erradicação da pobreza, dentre outros (ABDALA; GONÇALVES, 2012).

Os dois últimos anos do período de busca, 2015 e 2016, também evidenciaram aumento no número de publicações. O considerável número de trabalhos de pesquisadores europeus neste contexto pode se relacionar ao fato da União Europeia atuar em projetos de eco inovação adotados a partir de dezembro de 2011 por meio de políticas e incentivos neste sentido e proposição de metas a serem cumpridas até 2020 (EC, 2017).

Os 10 artigos mais citados na amostra estão dispostos na Tabela 2. O mais citado nas duas bases foi Redefining innovation - eco-innovation research and the contribution from ecological economics de Klaus Rennings (2000), publicado na Ecological Economics. O autor aborda acerca das contribuições da economia ecológica para as pesquisas em eco inovação. $\mathrm{O}$ artigo deve ter sido muito citado por ser de cunho téorico e por trazer, além da integração entre aspectos econômicos, sociais e ambientais, as possíveis mudanças institucionais e sociais decorrentes de inovações voltadas à redução de impactos ambientais.

Dentre os dez trabalhos mais citados, 3 são teóricos: o de Rennings (2000), o de Schot e Geels (2008) e o estudo de Boons e Luedeke-Freund (2013). Quatro deles provém de estudos de caso ou de coleta de dados diretamente com gestores de empresas, a saber: o de Geffen e Rothenberg (2000), o de Chen et al. (2006), o de Chen (2008) e o de Pujari (2006). Outros três artigos são resultantes de pesquisas com utilização de dados secundários provenientes de orgãos dos governos ou de outras base de dados.

Tabela 2: Artigos mais citados - Bases Web of Science /Scopus (Elsevier).

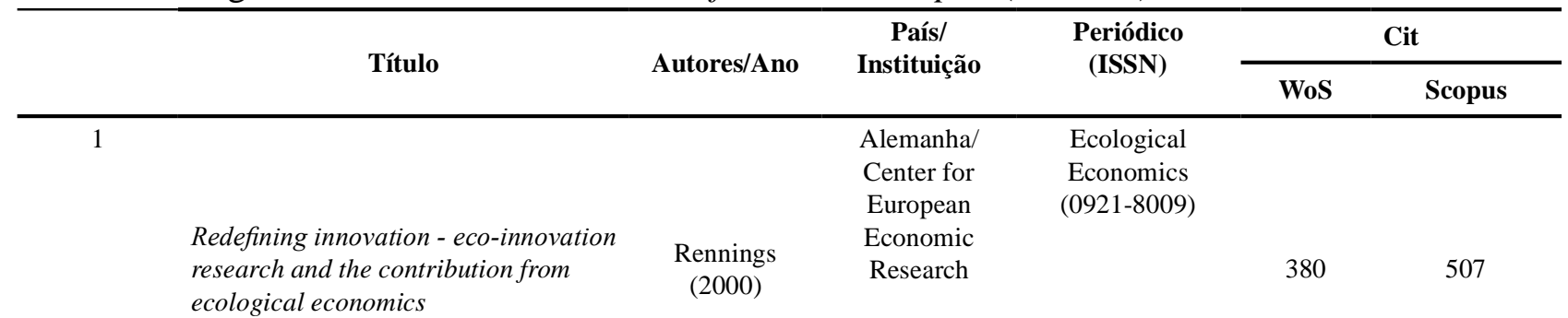




\begin{tabular}{|c|c|c|c|c|c|c|}
\hline 2 & $\begin{array}{l}\text { Strategic niche management and } \\
\text { sustainable innovation journeys: } \\
\text { theory, findings, research agenda, and } \\
\text { policy }\end{array}$ & $\begin{array}{l}\text { Schot \& Geels } \\
(2008)\end{array}$ & $\begin{array}{l}\text { Holanda/ } \\
\text { Eindhoven } \\
\text { University of } \\
\text { Tecnology }\end{array}$ & $\begin{array}{l}\text { Technology } \\
\text { Analysis \& } \\
\text { Strategic } \\
\text { Management } \\
(0953-7325)\end{array}$ & 263 & 346 \\
\hline 3 & $\begin{array}{l}\text { Determinants of environmental } \\
\text { innovation in US manufacturing } \\
\text { industries }\end{array}$ & $\begin{array}{l}\text { Brunnermeier } \\
\text { \& Cohen } \\
\text { (2003) }\end{array}$ & $\begin{array}{l}\text { Estados } \\
\text { Unidos/ } \\
\text { Princeton } \\
\text { University }\end{array}$ & $\begin{array}{c}\text { Journal of } \\
\text { Environmental } \\
\text { Economics and } \\
\text { Management } \\
(0095-0696)\end{array}$ & 258 & 317 \\
\hline 4 & $\begin{array}{l}\text { Determinants of environmental } \\
\text { innovation - New evidence from } \\
\text { German panel data sources }\end{array}$ & $\begin{array}{l}\text { Horbach } \\
(2008)\end{array}$ & $\begin{array}{l}\text { Alemanha/ } \\
\text { University } \\
\text { of Applied } \\
\text { Sciences } \\
\text { Anhalt }\end{array}$ & $\begin{array}{c}\text { Research Policy } \\
\text { (0048-7333) }\end{array}$ & 230 & 282 \\
\hline 5 & $\begin{array}{l}\text { Suppliers and environmental } \\
\text { innovation - The automotive paint } \\
\text { process }\end{array}$ & $\begin{array}{c}\text { Geffen \& } \\
\text { Rothenberg } \\
(2000)\end{array}$ & $\begin{array}{c}\text { Estados } \\
\text { Unidos/ } \\
\text { Pacific } \\
\text { Northwest } \\
\text { National } \\
\text { Laboratory }\end{array}$ & $\begin{array}{l}\text { International } \\
\text { Journal of } \\
\text { Operations \& } \\
\text { Production } \\
\text { Management } \\
(0144-3577)\end{array}$ & 206 & 259 \\
\hline 6 & $\begin{array}{l}\text { The influence of green innovation } \\
\text { performance on corporate advantage } \\
\text { in Taiwan }\end{array}$ & $\begin{array}{l}\text { Chen, Lai \& } \\
\text { Wen (2006) }\end{array}$ & $\begin{array}{c}\text { China } \\
\text { University } \\
\text { of Science \& } \\
\text { Technology in } \\
\text { Taiwan }\end{array}$ & $\begin{array}{c}\text { Journal of } \\
\text { Business Ethics } \\
(1573-0697)\end{array}$ & 206 & 249 \\
\hline 7 & $\begin{array}{l}\text { The driver of green innovation and } \\
\text { green image - Green core competence }\end{array}$ & Chen (2008) & $\begin{array}{l}\text { China/ } \\
\text { University } \\
\text { of Science \& } \\
\text { Technology, } \\
\text { Taiwan }\end{array}$ & $\begin{array}{c}\text { Journal of } \\
\text { Business Ethics } \\
(1573-0697)\end{array}$ & 161 & 198 \\
\hline 8 & $\begin{array}{l}\text { Determinants of eco-innovations } \\
\text { by type of environmental impact - } \\
\text { The role of regulatory push/pull, } \\
\text { technology push and market pull }\end{array}$ & $\begin{array}{l}\text { Horbach, } \\
\text { Rammer \& } \\
\text { Rennings } \\
\text { (2012) }\end{array}$ & $\begin{array}{l}\text { Alemanha/ } \\
\text { University } \\
\text { of Applied } \\
\text { Sciences } \\
\text { Augsburg }\end{array}$ & $\begin{array}{l}\text { Ecological } \\
\text { Economics } \\
(0921-8009)\end{array}$ & 155 & - \\
\hline 9 & $\begin{array}{l}\text { Business models for sustainable } \\
\text { innovation: state-of-the-art and steps } \\
\text { towards a research agenda }\end{array}$ & $\begin{array}{c}\text { Boons \& } \\
\text { Luedeke- } \\
\text { Freund }(2013)\end{array}$ & $\begin{array}{l}\text { Holanda/ } \\
\text { Erasmus } \\
\text { University } \\
\text { Rotterdam }\end{array}$ & $\begin{array}{l}\text { Journal of } \\
\text { Cleaner } \\
\text { Production } \\
(0959-6526)\end{array}$ & 154 & 187 \\
\hline 10 & $\begin{array}{l}\text { Eco-innovation and new product } \\
\text { development: understanding the } \\
\text { influences on market performance }\end{array}$ & Pujari (2006) & $\begin{array}{l}\text { Canadá/ } \\
\text { McMaster } \\
\text { University }\end{array}$ & $\begin{array}{l}\text { Technovation } \\
(0166-4972)\end{array}$ & 149 & 185 \\
\hline
\end{tabular}

Fonte: Elaborado pelos autores.

A seguir, tem-se a rede de autores dos trabalhos encontrados na amostra (Figura 2). Ela apresenta os pesquisadores que publicaram pelo menos 4 trabalhos sobre o tema no período analisado. Esta abordagem é importante pois demonstra os relacionamentos de parcerias e co-autorias nos trabalhos. Considerou-se 4 trabalhos como o número mínimo para estarem na rede devido ao grande número de pesquisadores evidenciados neste contexto.

Identificou-se que Yu-Shan Chen, da Universidade de Ciência e Teconologia de Taiwan, foi quem mais publicou no período, com um total de 15 trabalhos. Sua primeira publicação sobre o tema foi no ano de 2006 e seus trabalhos trataram, em grande parte, sobre a obtenção de vantagem competitiva por parte das empresas a partir da atuação em eco inovação. 
Figura 2: Rede de co-autoria dos 618 artigos.

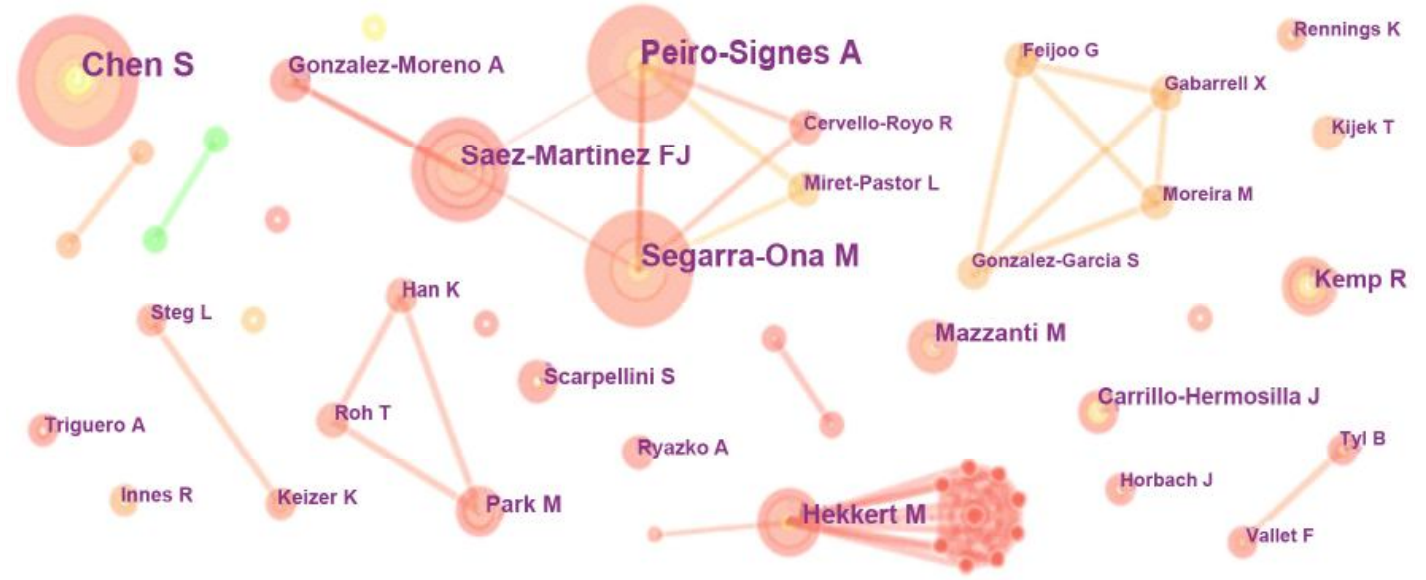

Fonte: Elaborado pelos autores por meio do uso do software Citespace.

Nota: Na figura são apresentados os autores que aparecem com frequência maior que 4. Os nós com cores mais claras representam publicações mais antigas enquanto as cores mais escuras represnetam publicações mais recentes.

Em segundo lugar, em número de publicações, estão os autores espanhóis Marival SegarraOña, Peiró-Signes, da Universidade Politécnica de Valência e Francisco Jose Saez-Martinez, da Univesridade de Castilla-La Mancha. Estes autores realizaram publicações em conjunto e formam relevante rede de co-autoria sobre eco inovações. Eles iniciaram as publicações sobre o tema em 2011. Pesquisaram acerca da eco inovação em empresas do setor de serviços e também em indústrias dos ramos de tecnologia, de cerâmica, automotivo e de construção.

Quanto aos periódicos que mais publicaram sobre o assunto, evidenciou-se o Journal Of Cleaner Production como o mais relevante. A Tabela 3 apresenta a frequência e o percentual do total de publicações sobre o tema nos referidos periódicos. Xavier et al. (2017) também evidenciou a importância do Journal of Cleaner Production nas publicações sobre o tema.

Tabela 3: Periódicos que mais publicaram - Bases Web of Science / Scopus (Elsevier).

\begin{tabular}{|c|c|c|c|c|c|}
\hline Periódicos & Freq. & Percentual & ISSN & $\begin{array}{l}\text { JCR } \\
(2016)\end{array}$ & H-Scopus \\
\hline Journal Of Cleaner Production & 66 & $10,68 \%$ & $0959-6526$ & 3,541 & 5,87 \\
\hline Sustainability & 20 & $3,24 \%$ & 2071-1050 & 1,161 & 2,35 \\
\hline Business Strategy and The Environment & 15 & $2,43 \%$ & 0964-4733 & 2,804 & 5,48 \\
\hline Research Policy & 14 & $2,27 \%$ & $0048-7333$ & 3,963 & 6,34 \\
\hline Technological Forecasting and Social Change & 14 & $2,27 \%$ & $0040-1625$ & 2,095 & 3,38 \\
\hline Ecological Economics & 13 & $2,10 \%$ & 0921-8009 & 2,665 & 3,59 \\
\hline Industry And Innovation & 10 & $1,62 \%$ & $1366-2716$ & 0,701 & 1,16 \\
\hline $\begin{array}{l}\text { International Journal of Innovation and } \\
\text { Sustainable Development }\end{array}$ & 8 & $1,29 \%$ & $1740-8830$ & - & 0,70 \\
\hline $\begin{array}{l}\text { Environmental Engineering and Management } \\
\text { Journal }\end{array}$ & 7 & $1,13 \%$ & $1582-9596$ & 0,420 & 0,72 \\
\hline Technology Analysis \& Strategic Management & 7 & $1,13 \%$ & $0953-7325$ & 0,993 & 1,56 \\
\hline Parcial & 174 & $28,16 \%$ & & \multirow{2}{*}{ JCR } & \multirow{2}{*}{$\begin{array}{l}\text { Cite } \\
\text { Score }\end{array}$} \\
\hline Outros periódicos & 444 & $71,84 \%$ & & & \\
\hline Total & 618 & $100,00 \%$ & Média & 2,038 & 3,115 \\
\hline
\end{tabular}

Fonte: Elaborado pelos autores. Nota: Fator de Impacto sem autocitação. Legenda: Freq. = Frequência. 
A Figura 3 apresenta a rede dos países que publicaram acerca da temática, o nome dos dez países com maior volume de trabalhos sobre a temática foi mantido, para demonstrar quais os países mais relevantes quanto ao volume de publicações sobre o assunto. Dentre eles, os pesquisadores dos Estados Unidos (EUA) foram os mais representativos em número de publicações (110 trabalhos), seguidos pelos pesquisadores da Espanha (104 trabalhos) e do Reino Unido (79 trabalhos). Podese evidenciar que os pesquisadores dos EUA publicaram com autores de outros treze países, principalmente, com pesquisadores da França e também, de forma relevante, com autores da China e da Alemanha.

Figura 3: Países em que os pesquisadores mais publicaram.

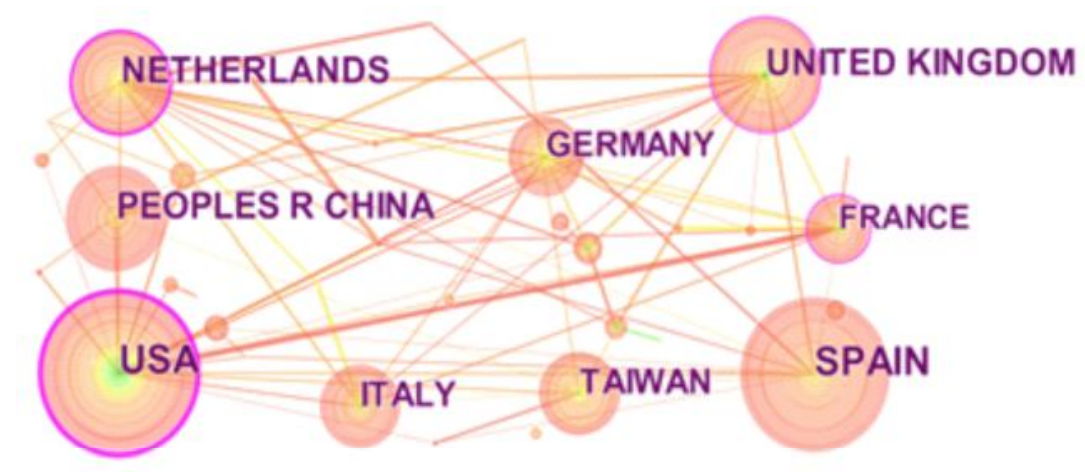

\begin{tabular}{ccc}
\hline N. & Centr. & País/Ano de Início \\
\hline 110 & 0.44 & USA (1996) \\
\hline 104 & 0.29 & Spain (2007) \\
\hline 79 & 0.20 & United Kingdom (1998) \\
\hline 70 & 0.13 & China (2010) \\
\hline 68 & 0.09 & Netherlands (2008) \\
\hline 60 & 0.08 & Taiwan (2004) \\
\hline 59 & 0.08 & Italy (1998) \\
\hline 57 & 0.08 & Germany(2005) \\
\hline 48 & 0.07 & France (1996) \\
\hline 23 & 0.06 & Denmark, (2002) \\
\hline
\end{tabular}

Fonte: Elaborado pelos autores por meio do uso do software Citespace. Legenda: N. = número de artigor por país; Centr. = centralidade do país na rede.

As publicações dos pesquisadores dos EUA sobre a temática iniciaram-se a partir de 1996. O artigo mais citado do país (317 citações pela amostra) foi a obra de Brunnermeier e Cohen (2003), intitulada Determinants of environmental innovation in US manufacturing industries.

Outra análise relevante é a rede de palavras-chave (Figura 4) pois permite identificar as principais temáticas discutidas no campo de estudo. $\mathrm{Na}$ rede da figura 4 estão as palavras-chave encontradas com frequência maior que 32.

Figura 4: Rede de palavras-chave nos 618 artigos

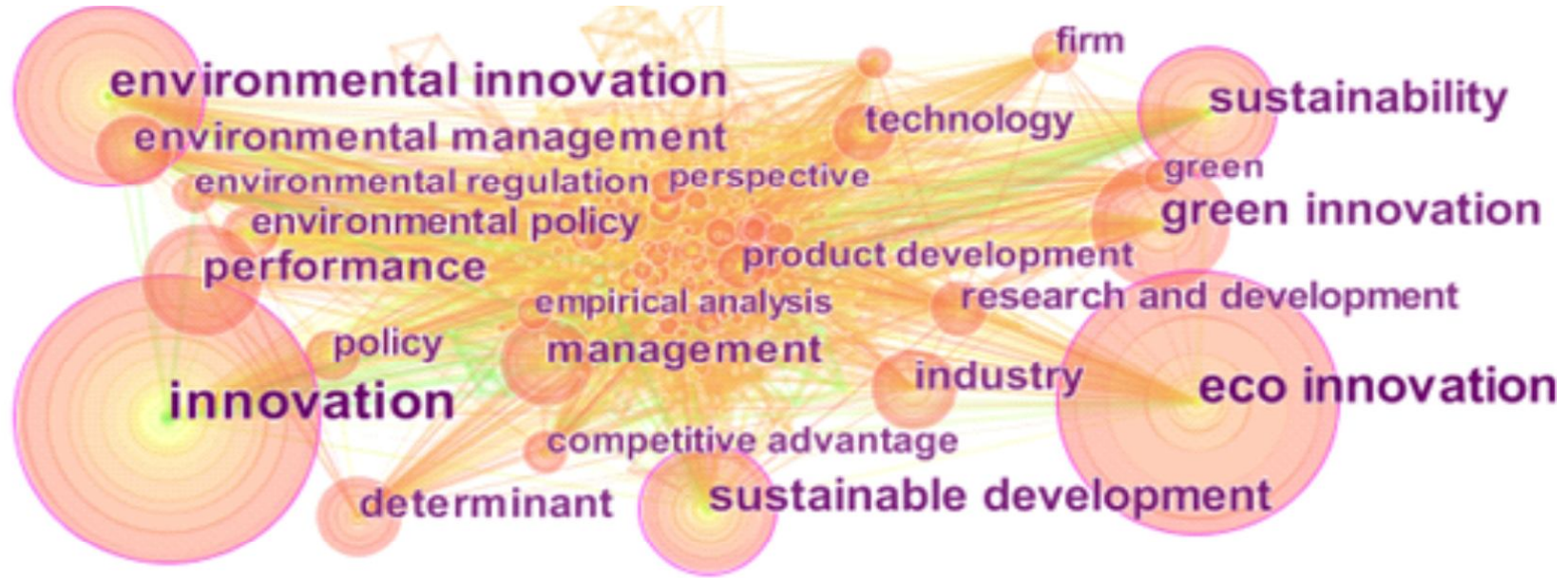

Fonte: Elaborado pelos autores por meio do uso do software Citespace. Legenda: palavras com frequência maior que 32. 
A partir da análise, evidenciou-se que innovation e eco innovation foram as palavras chave mais frequentes nos artigos da amostra. Os termos environmental innovation, sustainable development, sustainability e green innovation também se destacaram em representatividade nas palavras chave dos artigos.

A Tabela 4 apresenta as palavras-chave que aparecem no mínimo 32 vezes, a frequência evidenciada nos trabalhos e o artigo mais referenciado que usou cada palavra-chave. As palavraschave fornecem informações acerca do conteúdo dos artigos e se referem à abrangência de um assunto e de seus conceitos principais (MIGUÉIS et al., 2013).

Tabela 4: Palavras-chave nos artigos e artigo central por palavra-chave

\begin{tabular}{|c|c|c|c|c|c|}
\hline Palavra-chave & Frequência & Referência & Palavra-chave & Frequência & Referência \\
\hline innovation & 245 & Rennings (2000) & technology & 55 & Schot \& Geels (2008) \\
\hline eco innovation & 218 & $\begin{array}{l}\text { Horbach, Rammer \& } \\
\text { Rennings (2012). }\end{array}$ & $\begin{array}{l}\text { environmental } \\
\text { policy }\end{array}$ & 53 & $\begin{array}{l}\text { Horbach, Rammer \& Rennings } \\
\text { (2012) }\end{array}$ \\
\hline environmental innovation & 154 & $\begin{array}{l}\text { Brunnermeier \& Cohen } \\
\text { (2003) }\end{array}$ & policy & 51 & Horbach (2008) \\
\hline sustainable development & 114 & Chen, Lai \& Wen (2006) & $\begin{array}{l}\text { research and } \\
\text { development }\end{array}$ & 49 & Kesidou \& Demirel (2012) \\
\hline sustainability & 113 & Schot \& Geels (2008) & $\begin{array}{c}\text { product } \\
\text { development }\end{array}$ & 44 & $\begin{array}{c}\text { Triguero, Moreno-Mondéjar \& } \\
\text { Davia, (2013) }\end{array}$ \\
\hline green innovation & 110 & Chen, Lai \& Wen (2006) & firm & 42 & Chen, Lai \& Wen (2006) \\
\hline performance & 98 & Chen (2008) & $\begin{array}{l}\text { environmental } \\
\text { regulation }\end{array}$ & 42 & Chen (2008) \\
\hline management & 78 & Chen (2008) & $\begin{array}{l}\text { competitive } \\
\text { advantage }\end{array}$ & 40 & Chen, Lai \& Wen (2006) \\
\hline industry & 71 & De Marchi (2012) & perspective & 34 & Demirel \& Kesidou (2011) \\
\hline determinant & 69 & $\begin{array}{l}\text { Boons \& Lüdeke-Freund } \\
\text { (2013) }\end{array}$ & green & 34 & Boons et al. (2013) \\
\hline environmental management & 65 & Chiou et al. (2011) & empirical analysis & 32 & $\begin{array}{l}\text { Horbach, Rammer \& Rennings } \\
\text { (2012). }\end{array}$ \\
\hline
\end{tabular}

Fonte: Elaborado pelos autores por meio do uso do software Citespace.

stes resultados são relevantes, pois demonstram a interdisciplinaridade que a temática possui, revelando também que determinadas áreas do conhecimento tem familiaridade com determinados termos. No próximo tópico, são apresentados os resultados encontrados para a análise da rede de cocitações realizada a partir da amostra (Intellectual base).

\subsection{ANÁLISE DA REDEDE COCITAÇÕES REALIZADA PELAAMOSTRA(INTELLECTUALBASE)}

A Intellectual base permite a análise da rede das obras mais citadas dentre os artigos da amostra. Esta representa as obras que mais têm influenciado novos trabalhos dentro do campo de estudos em questão (Figura 5).

Quanto aos trabalhos mais relevantes de acordo com a contagem de citações na própria amostra, a obra Redefining innovation - eco-innovation research and the contribution from ecological economics, de Rennings (2000), é o primeiro com o total de 198 citações. O segundo é de Horbach (2008), intitulado Determinants of environmental innovation - New evidence from German panel data sources com 152 citações. Já o terceiro é o trabalho Toward a new conception of the environmentcompetitiveness relationship de Porter e Van der Linde (1995), com 149 citações. 
Figura 5: Rede de artigos citados na amostra.

\section{REHFELD KM (2007)}

\section{HORBACH J (2008)}

\section{CHEN YS (2006)}

\section{BRUNNERMEIER SB (2003)}

\section{CARRILLO-HERMOSILLA J (2010)}

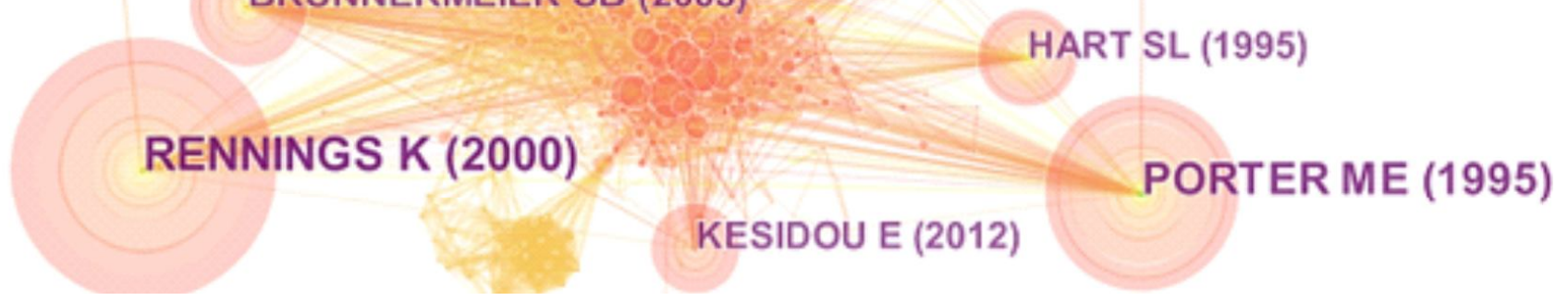

Fonte: Elaborado pelos autores por meio do uso do software Citespace.

Legenda: nomeados os artigos com frequência maior que 118 citações.

Dando continuidade às análises da Intellectual base, identificou-se a rede dos periódicos mais citados dentre os artigos constituintes da amostra (Figura 6). Esta rede apresenta os periódicos que possuem mais aceitação dentro da temática no que se refere ao conteúdo publicado pelos periódicos.

Figura 6: Rede de periódicos citados na amostra.

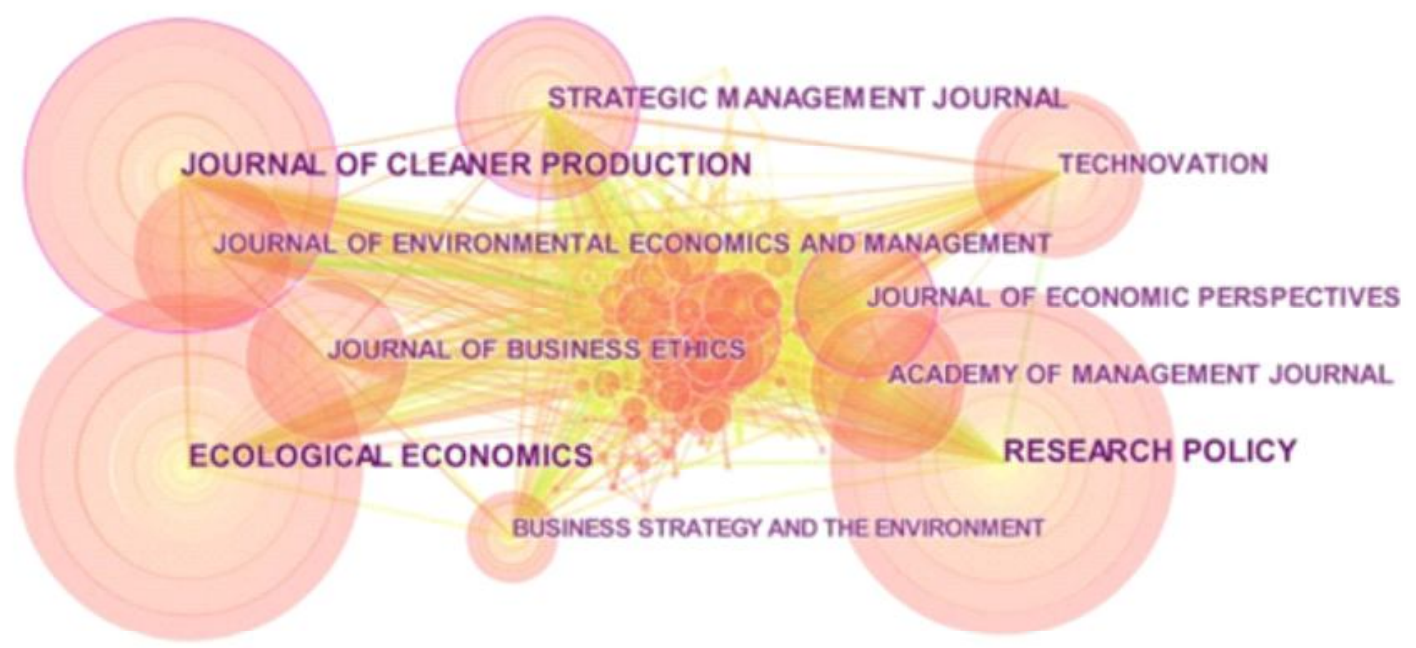

Fonte: Elaborado pelos autores por meio do uso do software Citespace.

Legenda: nomeados os periódicos com frequência maior que 109.

Na Figura 6, evidenciou-se que o periódico mais representativo é o Research Policy com 387 citações pela amostra. Em segundo lugar está o periódico Ecological Economics com 384 citações, em terceiro o Journal of Cleaner Production com 343 citações. 


\section{TENDÊNCIAS PARA ESTUDOS FUTUROS}

Para identificação de tendências para pesquisas futuras, os artigos presentes na amostra publicados em 2016 foram analisados com respeito às lacunas na literatura científica verificadas pelos autores dos trabalhos. As tendências encontradas se referiram a duas categorias principais: (i) aspectos metodológicos dos estudos e (ii) abordagens teóricas e conceituais. A Figura 7 apresenta estes dados e se trata de uma síntese dos tópicos identificados, realçando a coocorrência destes tópicos nos artigos

Figura 7: Mapa de direcionamento de pesquisa futuras e artigos correspondentes.

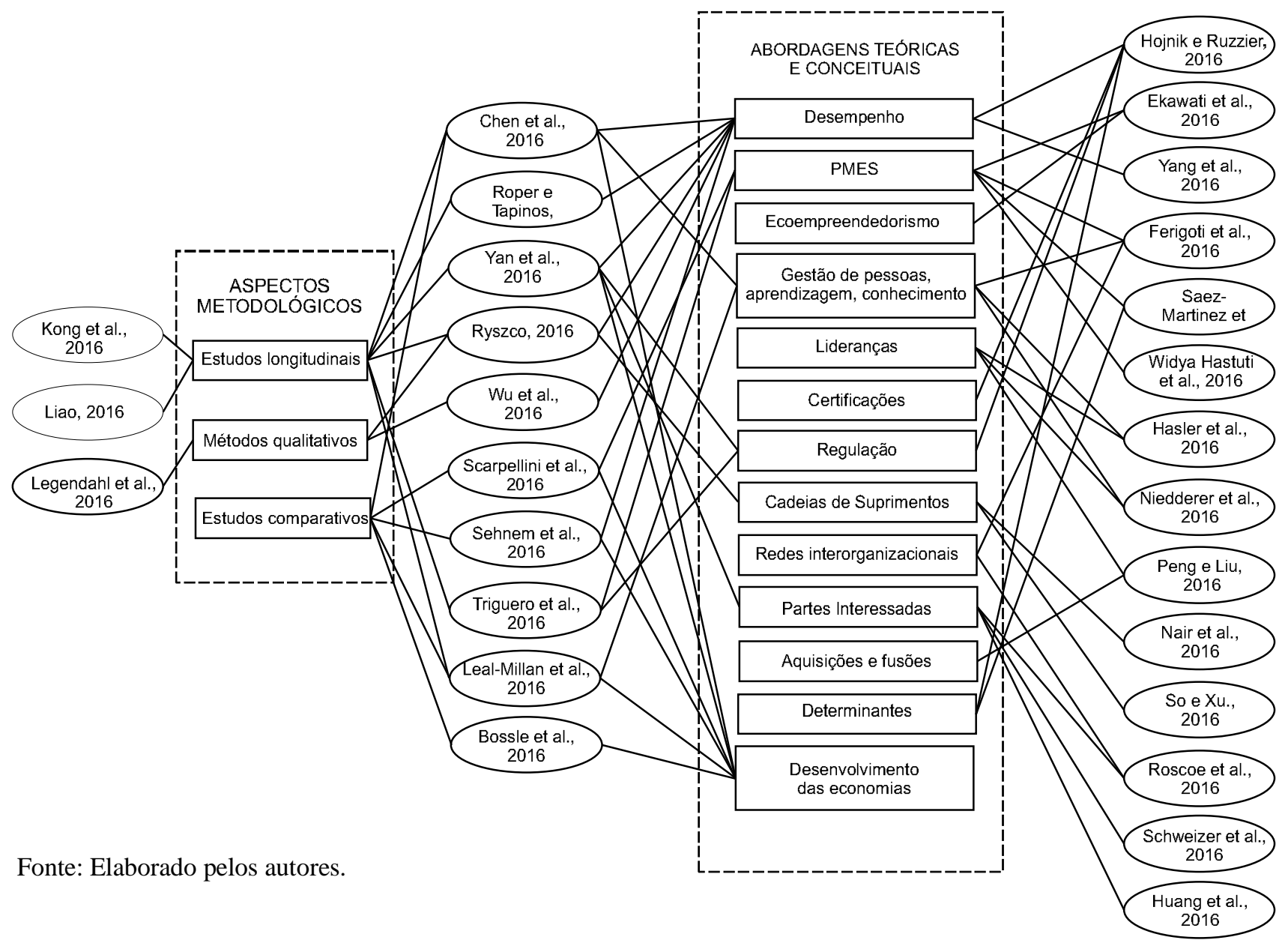

O Quadro 2, a seguir, apresenta, de forma mais detalhada, as tendências para estudos futuros encontradas nos artigos analisados. 
Quadro 2 - Tendências de pesquisas futuras e autores que as sugerem

\begin{tabular}{|c|c|c|}
\hline Tendências & Subtópicos & Autores \\
\hline Estudos longitudinais & $\begin{array}{l}\text { Estudos longitudinais (avaliar resultados da eco inovação nas } \\
\text { empresas no decorrer do tempo) }\end{array}$ & $\begin{array}{l}\text { CHEN et al., 2016; KONG et al., 201t } \\
\text { LEAL-MILLAN et al., 2016; LLAO, } \\
\text { 2016; ROPER; TAPINOS, 2016; } \\
\text { RYSZCO, 2016; TRIGUERO et al., } \\
\text { 2016; YAN et al., } 2016\end{array}$ \\
\hline Métodos qualitativos & $\begin{array}{l}\text { Utilização de técnicas qualitativas nos estudos sobre eco } \\
\text { inovação }\end{array}$ & $\begin{array}{l}\text { LEGENDAHL et al., 2016; RYSZkO, } \\
2016 \mathrm{a} \text {; WU et al., } 2016\end{array}$ \\
\hline Estudos comparativos & $\begin{array}{l}\text { Comparar adoção da eco inovação em diferentes empresas } \\
\text { situadas em países diversos }\end{array}$ & $\begin{array}{l}\text { BOSSLE } \text { et al., 2016; CHEN et al., } \\
\text { 2016; LEAL-MILLAN et al., } 2016 \text {; } \\
\text { SCARPELLINI et al., 2016; SEHNEN } \\
\text { et al., } 2016\end{array}$ \\
\hline \multirow[t]{2}{*}{ Desempenho } & Resultados da eco inovação incremental e radical & HOJNIK; RUZZIER, 2016 \\
\hline & Resultados da eco inovação para o desempenho das empresas & $\begin{array}{l}\text { CHEN et al., 2016; ROPER; TAPINO } \\
\text { 2016; SEHNEM et al., 2016; WU et a } \\
\text { 2016; YAN et al., 2016; YANG et al., } \\
2016\end{array}$ \\
\hline
\end{tabular}

Estudos comparativos entre resultados da eco inovação em diferentes tipos de negócios (tamanhos diferenciados e/ou

RYSZKO, 2016a; SEHNEM et al., áreas de atuação distintas)

Eco inovações e desenvolvimento de novos produtos

YANG et al., 2016

Pequenas e Médias Empresas Fco inovação em PMEs (Pequenas e Médias Empresas) (PMEs)

FKAWATI et al., 2016; FERIGOTI el al., 2016; SAEZ-MARTINEZ et al., 2016; TRIGUERO et al., 2016; WIDY HASTUTI et al., 2016

Determinantes da orientação ambiental de jovens PMEs

SAEZ-MARTINEZ et al., 2016

Impactos da eco inovação em PMEs para a sociedade

FERIGOTI et al., 2016; SCARPELLI. et al., 2016a

\begin{tabular}{ll}
\hline Ecoempreendedorismo & Ecoempreendedorismo e eco inovação em PMEs \\
\hline $\begin{array}{l}\text { Gestão de pessoas, } \\
\text { aprendizagem, conhecimento }\end{array}$ & Aprendizagem e fluxo de conhecimento para a eco inovação
\end{tabular}

EKAWATI et al., 2016

FERIGOTI et al., 2016; HASLER et a 2016; LEAL-MILLAN et al., 2016;

NIEDDERER et al., 2016

Avaliar práticas de recursos humanos em projetos de eco inovação

CHEN et al., 2016;

\section{Liderança}

Avaliar relação entre conhecimento, consciência ambiental e engajamento de gestores na eco inovação

HASLER et al., 2016; NIEDDERER $\epsilon$ al., 2016; PENG; LIU, 2016

\begin{tabular}{lll}
\hline Certificações & Efeito das certificações sobre a eco inovação nas empresas & HOJNIK; RUZZIER, 2016 \\
\hline Regulação & $\begin{array}{l}\text { Estudo acerca dos diferentes níveis de regulação e a relação } \\
\text { destes com a eco inovação em empresas inovadoras pioneiras, } \\
\text { seguidoras e em PMEs. }\end{array}$ & $\begin{array}{l}\text { HOJIGU; RUZZIER, 2016; } \\
2016\end{array}$
\end{tabular}

\begin{tabular}{lll}
\hline Cadeias de suprimentos & Gestão da cadeia de suprimentos para eco inovação & $\begin{array}{l}\text { NAIR et al., 2016; RYSZKO, 2016a; } \\
\text { SO; XU, 2016 }\end{array}$ \\
\hline Redes intereorganizacionais & Redes intereorganizacionais verdes & $\begin{array}{l}\text { FERIGOTI } \text { et al., 2016; ROSCOE } \text { et a } \\
2016\end{array}$ \\
\hline Partes interessadas & $\begin{array}{l}\text { Papel de partes interessadas como cidadãos, governos, } \\
\text { organizaçôes não-governamentais e funcionários das empresas } \\
\text { no funcionamento de cadeias de suprimentos verdes }\end{array}$ & $\begin{array}{l}\text { ROSCE } \text { al, 2016; SCHWEIZER } e \\
\text { Influência dos incentivos políticos, concorrência e mercado no HUANG } \text { et al., 2016; YAN et al., 201 } \\
\text { desempenho em eco inovação }\end{array}$ \\
\hline Aquisiçốes e Fusões & $\begin{array}{l}\text { Aquisições e fusões e sua interferência na eco inovação das } \\
\text { empresas }\end{array}$ & PENG; LIU, 2016 \\
\hline
\end{tabular}

Determinantes (drivers) $\quad$ Disntinguir e explorar os condutores da eco inovação $\quad$ HOJNIK; RUZZIER, 2016.
incremental e radical

SAEZ-MARTINEZ et al., 2016

\section{Desenvolvimento das economias}

Determinantes da orientação ambiental de jovens PMEs
BOSSLE et al. 2016; CHEN et al.,

2016; LEAL-MILLAN et al., 2016; SCARPELLINT et al., 2016; SEHNEI et al., 2016

Fonte: Elaborado pelos autores. 
A partir desta análise, evidenciou-se o predomínio de indicações por estudos longitudinais, ou seja, avaliar resultados da eco inovação no decorrer do tempo, de estudos comparativos, de análises sobre desempenho organizacional a partir da eco inovação, de pesquisas sobre eco inovação considerando-se as diferenças de desenvolvimento econômico dos países onde as empresas atuam e de estudos sobre eco inovações em pequenas e médias empresas.

\section{CONCLUSÃO}

Este trabalho confirmou a importância das eco inovações nas pesquisas científicas, indicando que este tipo de inovação é um fenômeno cada vez mais presente na atuação de muitas empresas e, portanto, estudado sob diferentes enfoques e por muitos pesquisadores de países diversos.

O objetivo deste estudo foi compreender melhor como está o campo de estudos e servir como fonte de orientações acerca de como a literatura sobre as eco inovações está estruturada, bem como apresentar diretrizes para pesquisas até então não suficientemente abordadas nos trabalhos já publicados. Assim, este trabalho foi importante no sentido de mapear as pesquisas mais relevantes na área de estudo, os principais autores, periódicos, países com trabalhos mais citados e a rede de relações entre as pesquisas e pesquisadores da área presentes nas bases de dados Web of Science e Scopus (Elsevier).

Evidenciou-se que, a partir do ano de 2011 houve elevado aumento no número de publicações no campo. Os pesquisadores do continente europeu foram os que mais publicaram sobre o tema, o que, provavelmente, está relacionado ao fato de a União Europeia fomentar pesquisas e atuações com metas de eco inovação para serem cumpridas até o ano de 2020.

O periódico que apresentou o maior número de trabalhos citados nos artigos da amostra foi o Ecological Economics. O trabalho mais citado pelos pesquisadores da área é do autor Rennings (2000), da Alemanha, intitulado Redefining innovation - eco-innovation research and the contribution from ecological economics, provavelmente por ser de cunho teórico e, assim, embasar muitas das discussões posteriores sobre o tema.

Quanto à agenda de estudos futuros elaborada a partir das sugestões dos autores das publicações do ano de 2016 presentes na amostra, observou-se que houve predomínio de indicações por estudos longitudinais, ou seja, de trabalhos que avaliem os resultados da eco inovação no decorrer do tempo, de estudos comparativos; de análises sobre implicações no desempenho organizacional a partir da eco inovação; de pesquisas sobre eco inovação em diferentes contextos de desenvolvimento econômico; e de estudos sobre eco inovações em pequenas e médias empresas.

Considera-se que as principais contribuições deste estudo tenham sido mapear as publicações existentes e fornecer caminhos aos pesquisadores da área sobre o campo de estudo e ter construído uma agenda de estudos futuros baseada nas sugestões dos autores dos trabalhos mais recentes da amostra de artigos. 


\section{REFERÊNCIAS}

ABDALA, V.; GONÇALVES, C. Documento final da Rio+20 é oficialmente adotado por mais de 190 países. Empresa Brasil de Comunicação, 2012.

ABDULLAH, M.; ZAILANI, S.; IRANMANESH, M.; JAYARAMAN, K. Barriers to green innovation initiatives among manufacturers: the Malaysian case. Review of Managerial Science. $v$. 10, p 683-709, october 2016, .

AMORES-SALVADO, J.; CASTRO, G. M.; NAVAS-LOPEZ, J. E. The importance of the complementarity between environmental management systems andenvironmental innovation capabilities: A firm level approach to environmental and business performance benefits.

Technological forecasting and social change, v. 96, p. 288-297, 2015.

ANGELO, F. D.; JABBOUR, C. J. C.; GALINA, S. V. Environmental innovation: in search of a meaning. World Journal of Entrepreneurship, Management and Sustainable Development, v. 8, p. 113-121, 2012.

BERNAUER, T.; ENGELS, E.; KAMMERER, D.; SEIJAS, J. Explaining green innovation: ten years after porter's win-win proposition: how to study the effects of regulation on corporate environmental innovation? Center for Comparative and International Studies. n. 17, 2006. BOONS, F.; LÜDEKE-FREUND, F. Business models for sustainable innovation: state-of-the-art and steps towards a research agenda. Journal of Cleaner Production, v. 45, p. 9-19, 2013. BOONS, F.; MONTALVO, C.; QUIST, J.; WAGNER, M. Sustainable innovation, business models and economic performance: an overview. Journal of Cleaner Production, v. 45, p. 1-8, 2013.

BOSSLE, M. B.; BARCELLOS, M. D.; VIEIRA, L. M.; SAUVÉE, L. The drivers for adoption of eco-innovation. Journal of Cleaner Production, n. 113, p. 861-872, 2016.

BRUNNERMEIER, S. B.; COHEN, M. A. Determinants of environmental innovation in US manufacturing industries. Journal of environmental economics and management, v. 45, n. 2, p. 278-293, 2003.

CARRILLO-HERMOSILLA, J.; DEL RÍO, P.; KÖNNÖLÄ, T. Diversity of eco-innovations: Reflections from selected case studies. Journal of Cleaner Production, v. 18, n. 10, p. 1073-1083, 2010.

CHANG, C-H. The Effect of Corporate Environmental Commitment on Green Product Innovation. Picmet '12, p. 1144-1151, 2012.

CHASSAGNON, V.; HANED, N. The relevance of innovation leadership for environmental benefits: A firm-level empirical analysis on French firms. Technological Forecasting and social change, v. 91, p. 194-207, 2015.

CHEN, C. CiteSpace II: Detecting and visualizing emerging trends and transient patterns in scientific literature. JASIST, v, 57, n. 3, p. 359-377. 2006.

CHEN, Y. S. The driver of green innovation and green image-green core competence. Journal of business ethics, v. 81, n. 3, p. 531-543, 2008. 
CHEN, Y. S.; LAI, S. B.; WEN, C. T. The influence of green innovation performance on corporate advantage in Taiwan. Journal of business ethics, v. 67, n. 4, p. 331-339, 2006.

CHIARVESIO, M.; DE MARCHI, V.; DI MARIA, E. Environmental innovations and internationalization: theory and practices. Business strategy and the environment. v. 24 n. 8, p. 790-801, 2015.

CHIOU, T. Y.; CHAN, H. K.; LETTICE, F.; CHUNG, S. H. The influence of greening the suppliers and green innovation on environmental performance and competitive advantage in Taiwan.

Transportation Research Part E: Logistics and Transportation Review, v. 47, n. 6, p. 822-836, 2011.

CHUEKE, G. V.; AMATUCCI, M. O que é bibliometria? Uma introdução ao Fórum. InternexT Revista Eletrônica de Negócios Internacionais da ESPM, v. 10, n. 2, p. 1-5, 2015

CLAVER, E. et al. Environmental management and firm performance: a case study. Journal of Environmental Management, v. 84, n. 4, p. 606-619, 2007.

DAI, J.; CANTOR, D. E.; MONTABON, F. L. How Environmental Management Competitive Pressure Affects a Focal Firm's Environmental. Journal of Business Logistics, v. 36, n. 3, p. 242259, 2015.

DE MARCHI, V. Environmental Innovation and R\&D Cooperation: Empirical Evidence from Spanish Manufacturing Firms. Research Policy, v. 41, n. 3, p. 614-623, 2012.

DECHEZLEPRETRE, A.; GLACHANT, M. Does foreign environmental policy influence domestic innovation? evidence from the Wind Industry. Environmental \& resource economics, v. 58, n. 3, p. 391-413, 2014.

DEMIREL, P.; KESIDOU, E. Stimulating different types of eco-innovation in the UK: Government policies and firm motivations. Ecological Economics, v. 70, n. 8, p. 1546-1557, 2011.

DORAN, J.; RYAN, G. The importance of the diverse drivers and types of environmental innovation for firm performance. Business strategy and the environment, v. 25, p. 102-119, 2016.

EC - EUROPEAN COMISSION. Environment: Eco-innovation Action Plan. Disponível em: https://ec.europa.eu/environment/ecoap/about-action-plan_en. Acesso em: 30 out 2017.

EIO - ECO-INNOVATION OBSERVATORY. A systemic perspective on eco innovation. Funded by the European Commission, DG Environment, Brussels, 2013.

FRAJ, E.; MATUTE, J.; MELERO, I. Environmental strategies and organizational competitiveness in the hotel industry: the role of learning and innovation as determinants of environmental success. Tourism Management, n. 46, p. 30-42, 2015.

GEFFEN, C. A.; ROTHENBERG, S. Suppliers and environmental innovation: the automotive paint process. International Journal of Operations \& Production Management, v. 20, n. 2, p. 166186, 2000.

GHISETTI, C.; PONTONI, F. Investigating policy and R \& D effects on environmental innovation: a meta-analysis. Ecological Economics, v. 118, p. 57-66, 2015. 
GILLI, M.; MAZZANTI, M.; NICOLLI, F. Sustainability and competitiveness in evolutionary perspectives: Environmental innovations, structural changes and economic dynamics in the EU. The Journal of Socio-Economics n. 45, p. 204-215, 2013.

HART, S. L. A natural-resource-based view of the firm. Academy of management review, v. 20, n. 4, p. 986-1014, 1995.

HORBACH, J. Determinants of environmental innovation-New evidence from German panel data sources. Research policy, v. 37, n. 1, p. 163-173, 2008.

HORBACH, J.; RAMMER, C.; RENNINGS, K. Determinants of eco-innovations by type of environmental impact - The role of regulatory push/pull, technology push and market pull. Ecological Economics, v. 78, p. 112-122, 2012.

JUNQUERA, B.; DEL BRÍO, J. Á.; FERNÁNDEZ, E. Clients' involvement in environmental issues and organizational performance in businesses: An empirical analysis. Journal of Cleaner Production, v. 37, p. 288-298, 2012.

KAMMERER, D. The effects of customer benefit and regulation on environmental product innovation. Empirical evidence from appliance manufactures in Germany. Ecological Economics, v. 68, n. $8 / 9$, p. $2285-2295,2009$.

KESIDOU, E.; DEMIREL, P. On the drivers of eco-innovations: Empirical evidence from the UK. Research Policy, v. 41, n. 5, p. 862-870, 2012.

LEE, K-H; KIM, J.-W. Green new product development and supplier involvement: Strategic partnership for green innovation. International Journal of Innovation and Sustainable

Development, v. 6, p. 290-304, 2012.

MIGUÉIS, A. et al. A importância das palavras-chave dos artigos científicos da área das Ciências Farmacêuticas, depositados no Estudo Geral: estudo comparativo com os termos atribuídos na MEDLINE. InCID: Revista de Ciência da Informação e Documentação, v. 4, n. 2, p. 112-125, 2013.

MIKLENCICOVA, R.; CAPKOVICOVA, B. Environmental management and green innovation in business. Marketing Identity: explosion of innovations, p. 482-493, 2014.

NAIR, A.; YAN, T.; RO, Y. K.; OKE, A.; CHILES, T. H.; LEE, S. Y. How Environmental Innovations Emerge and Proliferate in Supply Networks: A Complex Adaptive Systems Perspective. Journal of Supply Chain Management, v. 52, n. 2, p. 66-86, 2016.

OECD - ORGANINAÇÃO PARA COOPERAÇÃO E DESENVOLVIMENTO ECONÔMICO.

Manual de Oslo: diretrizes para coleta e interpretação de dados sobre inovação. Paris: OECD; Brasília: FINEP, 2006.

PACHECO, L. M; LIBONI, L. B. Dynamic capabilities for green innovations: a systematic literature review and propositions for future studies. ENANPAD 2017 -Encontro Nacional da Associação de Pós graduação em Administração, São Paulo / SP, 01 a 04 de Outubro de 2017. PINGET, A.; BOCQUET, R.; MOTHE, C. Barriers to environmental innovation in SMEs: empirical evidence from French firms. Management, v. 18, n. 2, p. 132-155, 2015. 
PINSKY, V. C. et al. Inovação sustentável: uma perspectiva comparada da literatura internacional e nacional. Revista de Administração e Inovação, v. 12, n. 3 p. 226-250, 2015.

PORTER, M. E.; VAN DER LINDE, C. Toward a new conception of the environmentcompetitiveness relationship. The journal of economic perspectives, v. 9, n. 4, p. 97-118, 1995.

PRADO, J. W. et al. Multivariate analysis of credit risk and bankruptcy research data: a bibliometric study involving different knowledge fields (1968-2014). Scientometrics, v. 106, n. 3, p. 1007-1029, 2016.

PUJARI, D. Eco-innovation and new product development: understanding the influences on market performance. Technovation, v. 26, n. 1, p. 76-85, 2006.

QUEVEDO-SILVA, F.; SANTOS, E. B. A.; BRANDÃO, M. M.; VILS, L. Estudo Bibliométrico: Orientações sobre sua Aplicação. Revista Brasileira de Marketing, v. 15, n. 2, p. 246-262, 2016. REHFELD, K. M.; RENNINGS, K.; ZIEGLER, A. Integrated product policy and environmental product innovations: An empirical analysis. Ecological economics, v. 61, n. 1, p. 91-100, 2007.

RENNINGS, K. et al. The influence of different characteristics of the EU environmental management and auditing scheme on technical environmental innovations and economic performance. Ecological Economics, v. 57, n. 1, p. 45-59, 2006.

RENNINGS, K. Redefining innovation - eco-innovation research and the contribution from ecological economics. Ecological economics, v. 32, n. 2, p. 319-332, 2000.

REXHAUSER, S.; RAMMER, C. Environmental innovations and firm profitability: unmasking the porter hypothesis. Environmental \& resource economics, v. 57, p. 45-67, 2014.

SÁNCHEZ, Á. P.; DEZA, X. V. Environmental policy instruments and eco-innovation: an overview of recent studies. Innovar. v. 25, n. 58, p. 65-80, 2015.

SCHOT, J.; GEELS, F. W. Strategic niche management and sustainable innovation journeys: theory, findings, research agenda, and policy. Technology Analysis \& Strategic Management, v. 20, n. 5, p. 537-554, 2008.

TRIGUERO, A.; MORENO-MONDEJAR, L.; DAVIA, M. Leaders and Laggards in Environmental Innovation: An Empirical Analysis of SMEs in Europe. Business strategy and the environment, v. 25, n. 1, p. 28-39, 2016.

TUFFANNI, M. Dez anos depois, Protocolo de Kyoto falhou em reduzir emissões mundiais.

Folha de São Paulo, 16 fevereiro de 2015. Disponível em: http://www1.folha.uol.com.br/ am biente/2015/02/1590476-dez-anos-depois-protocolo-de-kyoto-falhou-em-reduzir-emissoesmundiais.shtml. Acesso em: 01 set 2017.

XAVIER, A. F.; NAVEIRO, R. M.; AOUSSAT, A.; REYES, T. Systematic literature review of ecoinnovation models: opportunities and recommendations for future research. Journal of Cleaner Production, v.149, p. 1278-1302, 2017.

ZAILANI, S.; IRANMANESH, M.; NIKBIN, D.; JUMADI, H. B. Determinants and environmental outcome of green technology innovation adoption in the transportation industry in Malaysia. Asian Journal of technology innovation. v. 22, n. 2, p. 286-301, 2014. 